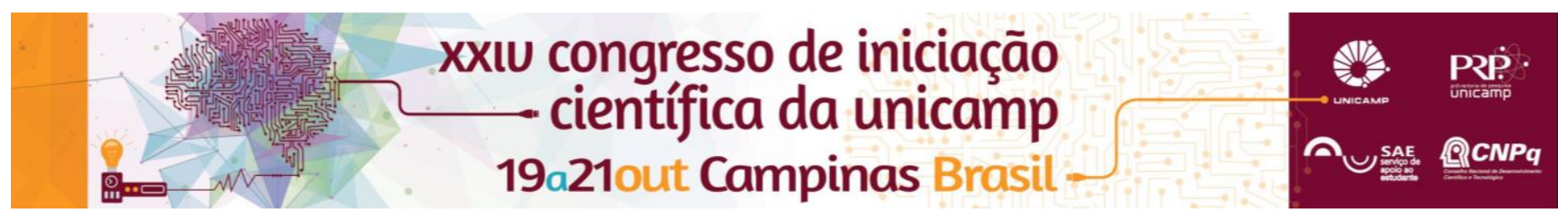

\title{
Estudos taxonômicos, ampliação e informatização das coleções de Echinodermata do Museu de Zoologia da Unicamp
}

\section{Letícia Dias de Oliveira*, Renata Alitto, Michela Borges.}

\section{Resumo}

As Coleções Científicas contêm valiosas informações taxonômicas, biológicas e geográficas, e servem de base para diversos estudos. A fim de maximizar a organização e qualidade das coleções de Echinodermata do ZUEC, que conta com mais de 52000 exemplares, neste trabalho refinamos a identificação de espécimes, adequação do acondicionamento, organização dos lotes e atualização das informações em banco de dados internos e online.

Palavras-chave: Echinodermos, coleção científica, biodiversidade.

\section{Introdução}

As Coleções Científicas Zoológicas, reuniões ordenadas de espécimes inteiramente fixados ou partes corporais destes, são fonte valiosa de informações taxonômicas, biológicas e geográficas, servindo como base fundamental para estudos ecológicos, ambientais ${ }^{1}$, entre outros. São poucas as coleções científicas marinhas no Brasil, especialmente de Echinodermata, um importante grupo de animais marinhos, composto por cerca de 7000 espécies viventes ${ }^{2}$. Atualmente são aceitas cinco classes: Crinoidea, Asteroidea, Ophiuroidea, Echinoidea e Holothuroidea. Neste contexto, as coleções de Echinodermata do Museu de Zoologia da Universidade Estadual de Campinas (ZUEC), atual referência no Estado e no Brasil, estão sendo reorganizadas e alguns grupos, em específico Ophiuroidea, estão sendo taxonomicamente estudados, com o objetivo de atender às necessidades da comunidade científica e levantar dados sobre sua biodiversidade.

\section{Resultados e Discussão}

Os estudos taxonômicos dos Ophiuroidea foram realizados a partir de espécimes depositados no Museu e que necessitavam de identificação ou revisão. Estes exemplares foram estudados por meio de literatura apropriada, descritos e ilustrados. Paralelamente ao trabalho taxonômico, as cinco coleções científicas que compõem 0 acervo de Echinodermata, ZUEC OPH (Ophiuroidea), ZUEC AST (Asteroidea), ZUEC ECH (Echinoidea), ZUEC HOL (Holothuroidea) e ZUEC CRI (Crinoidea), foram reorganizadas e todo material que aguardava tombamento foi catalogado. Os espécimes foram contabilizados, registrados nos respectivos livros tombo e armazenados em via úmida (álcool 70\%). Cada lote recebeu etiquetas contendo número de tombo, data, local de coleta e identificação taxonômica. Essas e outras informações complementares (p.e. profundidade e habitat) foram registradas nos cadernos de tombo e, posteriormente, banco de dados internos e on-line (www.cria.org.br). A organização das coleções segue a ordem alfabética de acordo com a família, gênero e espécie e, dentro de cada espécie por ordem crescente de número de tombo. Ainda, foi feita curadoria dos lotes já tombados afim de repor o líquido preservador, trocar vidrarias inapropriadas, e reorganizá-los de maneira mais prática, de pronta localização. Durante este trabalho, foram adicionados às coleções 189 lotes, 1072 espécimes de 17 espécies. Hoje há um total de 52843 equinodermos tombados no ZUEC, distribuídos em 34 famílias e 152 espécies (Fig. 1). Os Ophiuroidea são os mais representativos (Tab. 1), com mais de 52 mil espécimes e 128 espécies.

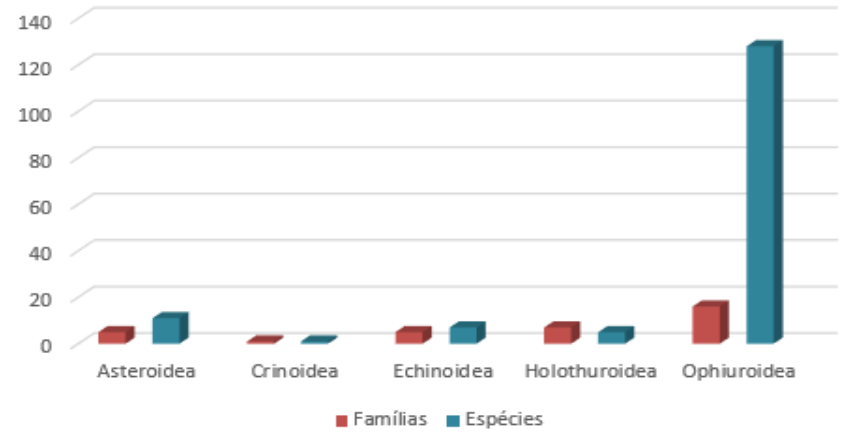

Figura 1. Quantidade de exemplares por família e espécie para cada coleção de Echinodermata do ZUEC.

Tabela 1. Número de exemplares tombados no ZUEC para cada Classe de Echinodermata.

\begin{tabular}{|c|c|}
\hline Classe & Quantidade de espécimes \\
\hline Asteroidea & 151 \\
\hline Crinoidea & 5 \\
\hline Echinoidea & 119 \\
\hline Holothuroidea & 195 \\
\hline Ophiuroidea & 52373 \\
\hline
\end{tabular}

\section{Conclusões}

A reorganização e estudo das coleções científicas de Echinodermata do ZUEC foram essenciais para o melhor conhecimento do grupo, não só com relação à sua biodiversidade, mas também morfologia e importância ecológica nos diferentes ambientes marinhos. A ampliação e estudo do acervo, curadoria e atualização dos bancos de dados, incrementaram a qualidade das coleções e colocaram o ZUEC como referência no estudo do grupo. Um diferencial é a informatização e disponibilização dos dados associados, para consultas inclusive remotas (online).

IPapavero, N. Fundamentos práticos de taxonomia zoológica. São Paulo: Editora da Universidade Estadual do Paulista, 1994.

${ }^{2}$ Pawson, David L. "Phylum echinodermata." Zootaxa 1668 (2007): 749-764. 